\title{
BMJ Open Racial ethnic differences in type 2 diabetes treatment patterns and glycaemic control in the Boston Area Community Health Survey
}

\author{
Sunali D Goonesekera, May H Yang, Susan A Hall, Shona C Fang, \\ Rebecca S Piccolo, John B McKinlay
}

To cite: Goonesekera SD, Yang $\mathrm{MH}$, Hall SA, et al. Racial ethnic differences in type 2 diabetes treatment patterns and glycaemic control in the Boston Area Community Health Survey. BMJ Open 2015;5:e007375 doi:10.1136/bmjopen-2014007375

\section{- Prepublication history and additional material is available. To view please visit the journal (http://dx.doi.org/ 10.1136/bmjopen-2014- 007375).}

Received 4 December 2014 Revised 17 March 2015 Accepted 27 March 2015

CrossMark

New England Research Institutes, Watertown, Massachusetts, USA

Correspondence to Sunali D Goonesekera; sunali2@yahoo.com

\section{ABSTRACT}

Objectives: Numerous studies continue to report poorer glycaemic control, and a higher incidence of diabetes-related complications among AfricanAmericans and Hispanic-Americans as compared with non-Hispanic Caucasians with type 2 diabetes. We examined racial/ethnic differences in receipt of hypoglycaemic medications and glycaemic control in a highly insured Massachusetts community sample of individuals with type 2 diabetes.

Setting: Community-based sample from Boston, Massachusetts, USA.

Participants: 682 patients with physician-diagnosed diabetes from the third wave of the Boston Area Community Health Survey (2010-2012). The study included approximately equal proportions of AfricanAmericans, Hispanics and Caucasians.

Methods: We examined racial/ethnic disparities in diabetes treatment by comparing proportions of individuals on mutually exclusive diabetes treatment regimens across racial/ethnic subgroups. Using multivariable linear and logistic regression, we also examined associations between race/ethnicity and glycaemic control in the overall population, and within treatment regimens, adjusting for age, gender, income, education, health insurance, health literacy, disease duration, diet and physical activity.

Results: Among those treated (82\%), the most commonly prescribed antidiabetic regimens were biguanides only (31\%), insulin only (23\%), and biguanides and insulin (16\%). No overall racial/ethnic differences in treatment or glycaemic control (per cent difference for African-Americans: $6.18,95 \% \mathrm{Cl}-1.00$ to 13.88; for Hispanic-Americans: $1.01,95 \% \mathrm{Cl}-10.42$ to 12.75) were observed. Within regimens, we did not observe poorer glycaemic control for African-Americans prescribed biguanides only, insulin only or biguanides combined with insulin/sulfonylureas. However, AfricanAmericans prescribed miscellaneous regimens had higher risk of poorer glycaemic control (per cent difference $=23.37,95 \% \mathrm{Cl} 7.25$ to 43.33). There were no associations between glycaemic levels and Hispanic ethnicity overall, or within treatment regimens.

Conclusions: Findings suggest a lack of racial/ethnic disparities in diabetes treatment patterns and glycaemic

\section{Strengths and limitations of this study}

- The study consisted of a community-based diverse racial/ethnic population with approximately equal proportions of black, Hispanic and white participants.

- Interviewers obtained detailed information on hypoglycaemic medication use by questioning participants, and inventorying prescription and over-the-counter medications.

- Information was obtained on actual receipt of medications rather than mere prescription events.

- The relatively small number of study participants within treatment regimens may have reduced our power to detect significant associations.

- As the study consisted of few uninsured patients with diabetes, we were unable to evaluate the effect of being uninsured on glycaemic control.

control in this highly insured Massachusetts study population. Future studies are needed to understand impacts of increasing insurance coverage on racial/ethnic disparities in treatment patterns and related outcomes.

\section{BACKGROUND}

Type 2 diabetes is increasingly prevalent in the USA and an estimated 29.1 million people were living with diagnosed and undiagnosed diabetes in 2012. ${ }^{1}$ Racial/ethnic minorities are disproportionately affected ${ }^{1}$ and have poorer glycaemic control, as well as a greater incidence of diabetes-related complications as compared with non-Hispanic Caucasians. ${ }^{2-10} \mathrm{~A}$ meta-analysis performed on 11 studies found greater mean glycated haemoglobin (HbAlc) levels among African-Americans compared with non-Hispanic Caucasians, ${ }^{5}$ and 15 out of 17 studies included in a systematic review found significantly elevated risk for poorer glycaemic control among African-Americans compared with white patients with diabetes. ${ }^{4}$ 
Possible explanations for these racial/ethnic disparities include poorer access to healthcare, more advanced disease at diagnosis, poorer adherence to medications, ${ }^{9-11}$ lesser degree of glucose self-monitoring ${ }^{4}$ and differences in health-related behaviours, such as diet and exercise. Disparities in access to newer high-cost medications may also contribute to racial/ethnic disparities in glycaemic control even among insured patients with diabetes. Multiple classes of hypoglycaemic medications, including thiazolidinediones, incretin mimetics, dipeptidyl peptidase-4 inhibitors, meglitinides, $\alpha$-glucosidase inhibitors and amylinomimetics, have been marketed to treat type 2 diabetes in recent decades. However, many of these medications are costlier than traditional classes of hypoglycaemic drugs such as insulins, sulfonylureas and biguanides. $^{12}{ }^{13}$ Even though metformin, a commonly prescribed biguanide, is relatively inexpensive and is effective at reducing $\mathrm{HbAlc}$ levels in many patients with diabetes, ${ }^{14}$ there is a great degree of individual variability in its efficacy. ${ }^{15}$ In addition, evidence suggests that certain newer medications such as long-acting glucagon-like peptide-1 agonists ${ }^{16}$ and combination therapies ${ }^{14-19}$ are more effective than standard medications at achieving HbA1c target levels in users. Whether healthcare providers are less inclined to prescribe these higher cost treatments to low-income, albeit insured, patients, irrespective of their race or ethnicity, remains unclear.

Evidence suggests that racial/ethnic disparities in type 2 diabetes management exist even within individual treatment facilities. ${ }^{20}$ However, few studies have directly examined racial/ethnic differences in diabetes medication utilisation. We used data from the Boston Area Community Health (BACH) Survey to examine racial/ ethnic differences in receipt of insulin and oral hypoglycaemic drugs for type 2 diabetes. The main objectives of our study were: (1) to identify differential treatment patterns across racial/ethnic subgroups; and (2) to identify effects of race/ethnicity on glycaemic control, independent of socioeconomic and behavioural factors in the overall population across and within treatment regimens. We performed analyses within treatment regimens based on the a priori hypothesis that racial/ethnic disparities in glycaemic control could differ by diabetes treatment. As minority patients may be diagnosed in more advanced stages of the disease as compared with white patients with diabetes, it is likely that they may have greater difficulty responding to certain types of hypoglycaemic treatments. The BACH cohort is well suited to evaluate disparities in treatment patterns due to its randomly sampled and community-based diverse racial/ ethnic population, and availability of detailed information on medication utilisation.

\section{METHODS}

Study design, participants and data collection

The BACH Survey is a population-based prospective cohort study. As detailed elsewhere, ${ }^{21}$ BACH investigators used multistage stratified cluster sampling to recruit approximately equal proportions of non-Hispanic Caucasian, non-Hispanic African-American and Hispanic participants from Boston, Massachusetts, USA, in three waves over 2002-2012; 5502 men and women aged 30-79 years were recruited during the first wave of data collection (BACH I; 2002-2005), and followed up in 2008-2010 (BACH II) and 2010-2012 (BACH III). Data for the current study are from BACH III. Of the BACH I and II participants, 3155 ( $81 \%$ conditional retention rate) participated in BACH III. During all waves, study participants were interviewed in their homes in English or Spanish. Anthropomorphic measurements (eg, height and weight) were obtained. Participants were questioned regarding diet, exercise, sleep quality, medication use, emotional health and comorbidities. In addition, medication containers were examined and medications were inventoried by the interviewers. During BACH III, investigators also obtained participants' blood samples to determine HbAlc levels. We restricted this analysis to 682 participants with self-reported physician-diagnosed type 2 diabetes (22\% of the BACH III cohort). All participants provided written informed consent.

\section{Ascertainment of hypoglycaemic medications}

In order to verify self-reported diabetes, interviewers collected information on hypoglycaemic medications prescribed by a healthcare provider and used more than once in the past 4 weeks by using a prompt by indication ("...for sugar in your blood") and by giving examples of relevant medications to improve accuracy of the data collected. ${ }^{23}$ In addition, participants' prescription and over-the-counter medication containers were examined and hypoglycaemic medications were inventoried by interviewers. Medication labels and/or responses were grouped by therapeutic class. Hypoglycaemic medications were initially grouped into one of the following most commonly prescribed regimens in this cohort: insulin only; biguanides only; insulin and biguanides; biguanides and sulfonylureas; sulfonylureas only; insulin and sulfonylureas; biguanides, sulfonylureas and thiazolidinediones; biguanides, insulin and sulfonylureas; and other combinations. Patients with diabetes who were untreated were categorised separately.

\section{Measurement of HbA1c levels}

HbAlc levels in blood samples were measured by Quest Diagnostics (Cambridge, Massachusetts, USA) using the HbAlc Tina quantitative assay with the Integra 800 chemistry analyser. We used a threshold of $\geq 7 \%$ to define poor glycaemic control, which is the National Glycohemoglobin Standardization Program (NGSP) ${ }^{24}$ and American Diabetes Association ${ }^{25}$ guidelines HbAlc target to reduce microvascular complications of diabetes.

\section{Measurement of covariates}

Body mass index (BMI): was calculated by dividing weight $(\mathrm{kg})$ by squared height $(\mathrm{m})$ and was categorised as 
$<25 \mathrm{~kg} / \mathrm{m}^{2}$ (normal/underweight), 25 to $<30 \mathrm{~kg} / \mathrm{m}^{2}$ (overweight) and $\geq 30 \mathrm{~kg} / \mathrm{m}^{2}$ (obese) according to current CDC guidelines. ${ }^{26}$

Socioeconomic status: We grouped socioeconomic variables into a priori determined categories based on prior literature: annual household income was categorised as < $\$ 20000, \$ 20$ 000-\$49 999 and $\geq \$ 50000$; education level was categorised as college or higher, some college or Associate's degree, high school completed and less than high school.

Health literacy and insurance status: Health literacy was assessed via the Short Test of Functional Health Literacy in Adults (STOFHLA) at the BACH III interview. ${ }^{27}$ The continuous scores were categorised as limited, marginal or adequate, based on previously validated cut-offs. ${ }^{27}$ We combined the limited and marginal categories as the latter had few participants. Investigators also recorded participants' health insurance status as public, private or uninsured. Private and public insurance categories were not mutually exclusive for all participants. Thus, we categorised participants according to whether or not they had private insurance. As there were only 11 participants with type 2 diabetes who were uninsured, we grouped them with participants who had no private insurance.

Behavioural risk factors: We obtained information on physical activity using Physical Activity Scale for the Elderly (PHASE) ${ }^{28}$ and diet using the Block food frequency questionnaire (FFQ) ${ }^{29}$ FFQ scores were assigned on a scale of $0-7$ based on the sum of the average daily intake of seven categories of nutrients (fruits, vegetables, grain, meat, fibre, saturated fat and sodium), with each category assigned a value of 1 if the recommended daily intake level for the component was met, or 0 otherwise. As the majority of the participants had low overall FFQ scores in this cohort, we created a dichotomous 'Healthy Eating Score', where a FFQ score $\geq 2$ was defined as healthy eating.

\section{Statistical analyses}

We performed multiple imputations for variables with missing data for each combination of race and gender using Multivariate Imputation by Chained Equations (MICE) $^{30}$ in R (R Foundation for Statistical Computing, Vienna, Austria) to minimise potential biases and reduction in precision. Thus, the analyses were performed on 15 imputed data sets. Most variables were missing for $<1 \%$ of observations. However, HbAlc values were missing for $29.2 \%$, income was missing for $31.9 \%$ and health literacy for $14.2 \%$. Thus, in order to satisfy the missing at random assumption, we specified a wide range of variables in the imputation models including all variables included in this analysis. We performed analyses using SUDAAN V.11 (Research Triangle Park, North Carolina, USA). The data were weighted by the inverse of the probability of being sampled at baseline (BACH I) to account for oversampling of minority groups. As there was greater attrition among males and participants in the lower socioeconomic levels, survey weights were adjusted for differential attrition by using the propensity cell adjustment approach, ${ }^{31}$ and poststratified to the Boston census population in 2010. We calculated the propensity score non-response weight adjustment using characteristics known for respondents and for non-respondents. We created a new weight by multiplying the original sample selection weight for each sample unit by the reciprocal of its modelling response propensity in order to estimate unbiased or nearly unbiased population statistics. ${ }^{31}$

We evaluated associations between race/ethnicity and glycaemic control $(\mathrm{y} / \mathrm{n})$ in the overall population adjusting for treatment regimen, and within individual mutually exclusive treatment regimens. Categories were further collapsed into broader strata to improve power for the regression analyses: biguanides only, insulin only, biguanides combined with either insulin or sulfonylureas, and other regimens. Post hoc power calculations performed for each stratum indicated that there was sufficient power $(80 \%)$ to detect a difference of at least 0.56 SDs for African-Americans and for HispanicAmericans $(\alpha=0.05)$, and none of the racial/ethnic groups consisted of less than 20 participants within any treatment stratum.

\section{Logistic regression}

HbA1c levels were dichotomised as $<7 \%$ vs $\geq 7 \%$ (glycaemic control vs poor control) and analyses were performed adjusting for (1) age and gender; (2) age, gender and BMI; and (3) age, gender, BMI, private health insurance (yes vs no), educational level, diabetes duration, income, Healthy Eating Score (low vs higher), caloric intake, physical activity and adequate health literacy (yes vs no). Diabetes duration was modelled as a quadratic function to improve the fit of the model after testing for linearity according to the $-2 \log$ likelihood and AIC scores. Linear and quadratic terms were both statistically significant. When performing analyses restricted to the insulin only and miscellaneous treatment regimens, we did not adjust for Healthy Eating Score to preserve model stability. We also performed sensitivity analyses using a $\mathrm{HbA1c}$ threshold of $\geq 8 \%$.

\section{Linear regression}

We performed multivariable linear regression to evaluate associations between race/ethnicity and continuous HbA1c levels adjusting for (1) age and gender; (2) age, gender and BMI; (3) age, gender, BMI, educational level, private health insurance (yes vs no), income level, diabetes duration (modelled as a quadratic function after testing for linearity using the $-2 \log$ likelihood and AIC scores), adequate health literacy (yes vs no), physical activity, Healthy Eating Score (low vs higher) and caloric intake. To normalise the residuals, we log transformed HbA1c levels and presented results as a percentage change in HbA1c levels. As in the logistic regression models, we performed analyses in the overall population adjusting for treatment, and within treatment regimens. 


\section{RESULTS}

Table 1 presents sociodemographic characteristics and degree of glycaemic control (HbAlc levels $\geq 7 \%$ vs $<7 \%$ ) in the overall study population, and by race/ethnicity among the 682 individuals with physician-diagnosed diabetes in this study. All percentages were weighted to adjust for stratified cluster sampling. A greater proportion of white participants were over the age of 65 years $(53 \%)$ as compared with African-Americans (36\%) and Hispanics $(30 \%)$. We also observed differences in socioeconomic variables across racial/ethnic groups. A greater proportion of Caucasians were college educated (40\%) as compared with African-Americans (14\%) and Hispanic-Americans $(6 \%)$, and a greater proportion had household incomes exceeding $\$ 50000$ (34\% vs $20 \%$ vs $11 \%$ for Caucasians, African-Americans and Hispanics, respectively). In addition, a smaller percentage of Caucasians had inadequate health literacy scores (20\%) as compared with African-Americans (45\%) and
Hispanics $(63 \%)$. The proportion of Hispanic participants who had private health insurance $(25 \%)$ was lower than that of African-American (39\%) and white participants $(45 \%)$. Behavioural variables such as diet and exercise were relatively evenly distributed across racial/ ethnic groups with most participants having low Healthy Eating Scores (71-83\%) and low levels of physical activity $(46-58 \%)$. We observed no significant differences in HbAlc levels across racial ethnic groups in this study population $(\mathrm{p}<0.14)$.

Most variables were evenly distributed between treated and untreated patients (table 2). We observed a greater proportion of women (63\% vs 48\%) and participants with college or advanced degrees (35\% vs $24 \%$ ) among the untreated compared with the treated, even though these differences were not statistically significant $\left(\chi^{2} \mathrm{p}\right.$ values of 0.06 and 0.30 , respectively). The untreated participants also had better HbAlc control compared with treated participants (HbA1c levels <7\%: $85 \%$ for

Table 1 Demographic characteristics and glycaemic control in the overall population and in racial/ethnic subgroups ( $N=682)$

\begin{tabular}{|c|c|c|c|c|c|}
\hline Variable & $\begin{array}{l}\text { Total } \\
\mathrm{N}=682 \\
\mathrm{~N}(\%) \dagger\end{array}$ & $\begin{array}{l}\text { Black } \\
\mathrm{N}=254 \\
\mathrm{~N}(\%) \dagger\end{array}$ & $\begin{array}{l}\text { Hispanic } \\
\mathrm{N}=269 \\
\mathrm{~N}(\%) \dagger\end{array}$ & $\begin{array}{l}\text { White } \\
N=159 \\
N(\%) \dagger\end{array}$ & p Value* \\
\hline \multicolumn{6}{|l|}{ Age (years) } \\
\hline$\geq 65$ & $291(44)$ & $102(36)$ & $103(30)$ & $86(53)$ & \multirow[t]{2}{*}{0.01} \\
\hline$<65$ & $391(56)$ & $152(64)$ & $166(70)$ & $73(47)$ & \\
\hline \multicolumn{6}{|l|}{ Gender } \\
\hline Male & 257 (49) & $89(44)$ & $100(51)$ & $68(52)$ & \multirow[t]{2}{*}{0.50} \\
\hline Female & $425(51)$ & $165(56)$ & $169(49)$ & $91(40)$ & \\
\hline \multicolumn{6}{|l|}{ Education } \\
\hline Less than high school & $232(18)$ & $63(23)$ & $145(46)$ & $24(7)$ & \multirow[t]{4}{*}{$<0.0001$} \\
\hline High school or equivalent & $220(34)$ & $90(36)$ & $75(36)$ & $55(32)$ & \\
\hline Some college/Associate's degree & $131(22)$ & $67(26)$ & $33(12)$ & $31(21)$ & \\
\hline College/advanced degree & $99(26)$ & $34(15)$ & $16(6)$ & $49(40)$ & \\
\hline \multicolumn{5}{|l|}{ Income } & \multirow[t]{4}{*}{0.01} \\
\hline$<\$ 20000$ & $410(49)$ & $126(46)$ & $198(68)$ & $85(47)$ & \\
\hline$\$ 20000-\$ 49999$ & $177(25)$ & $85(34)$ & $58(21)$ & $34(19)$ & \\
\hline$\$ 50000+$ & $95(26)$ & $43(20)$ & $13(11)$ & $40(34)$ & \\
\hline \multicolumn{6}{|l|}{ Private health insurance } \\
\hline Yes & $215(40.2)$ & $101(39)$ & $52(25)$ & $62(45)$ & \multirow[t]{2}{*}{0.01} \\
\hline No & $467(59.8)$ & $153(61)$ & $217(75)$ & $97(55)$ & \\
\hline \multicolumn{5}{|l|}{ Adequate health literacy } & \multirow[t]{3}{*}{$<0.0001$} \\
\hline Yes & $331(65)$ & $136(55)$ & $71(37)$ & $124(80)$ & \\
\hline No & $351(35)$ & $118(45)$ & $198(63)$ & $35(20)$ & \\
\hline \multicolumn{6}{|l|}{ Physical activity } \\
\hline Low & $385(53)$ & $134(46)$ & $156(54)$ & $95(58)$ & \multirow[t]{3}{*}{0.29} \\
\hline Medium & 253 (39) & $95(41)$ & $99(40)$ & $58(36)$ & \\
\hline High & $45(8)$ & $25(4)$ & $14(6)$ & $6(5)$ & \\
\hline \multicolumn{6}{|l|}{ Healthy Eating Scoreł } \\
\hline Low & $332(76)$ & $136(83)$ & $115(81)$ & $81(71)$ & \multirow[t]{2}{*}{0.25} \\
\hline Higher & 77 (24) & $30(17)$ & $18(19)$ & $29(29)$ & \\
\hline \multicolumn{6}{|l|}{ Glycaemic control } \\
\hline Poor (HbA1c $\geq 7 \%)$ & $312(43)$ & $115(49)$ & $137(50)$ & $60(36)$ & \multirow[t]{2}{*}{0.14} \\
\hline Adequate $(\mathrm{HbA} 1 \mathrm{c}<7 \%)$ & $370(57)$ & $139(51)$ & $132(50)$ & 99 (64) & \\
\hline
\end{tabular}

*Weighted column percentages are provided; percentages may not add up to $100 \%$ due to rounding and total numbers may not exactly add up as the average of 15 data sets are taken.

$+\chi^{2}$ Test.

†Frequency missing $=274$.

HbA1c, glycated haemoglobin. 
Table 2 Demographic characteristics and glycaemic control in treated and untreated patients with diagnosed type 2 diabetes $(\mathrm{N}=682)$

\begin{tabular}{|c|c|c|c|}
\hline Variable & $\begin{array}{l}\text { Treated } \\
\mathrm{N}=557 \\
\mathrm{~N}(\%) \dagger\end{array}$ & $\begin{array}{l}\text { Untreated* }^{*} \\
\mathrm{~N}=125 \\
\mathrm{~N}(\%) \dagger\end{array}$ & p Value \\
\hline \multicolumn{4}{|l|}{ Age (years) } \\
\hline$\geq 65$ & $236(44)$ & $55(45)$ & \multirow[t]{2}{*}{0.91} \\
\hline$<65$ & $321(56)$ & $70(55)$ & \\
\hline \multicolumn{4}{|l|}{ Gender } \\
\hline Male & $214(52)$ & $43(37)$ & \multirow[t]{2}{*}{0.06} \\
\hline Female & $343(48)$ & $82(63)$ & \\
\hline \multicolumn{4}{|l|}{ Race/ethnicity } \\
\hline Black & $204(38)$ & $50(36)$ & 0.82 \\
\hline Hispanic & $228(13)$ & $41(11)$ & 0.49 \\
\hline White & $125(49)$ & $34(53)$ & 0.62 \\
\hline \multicolumn{4}{|l|}{ Education } \\
\hline $\begin{array}{l}\text { Less than high } \\
\text { school }\end{array}$ & $193(19)$ & $39(13)$ & \multirow[t]{4}{*}{0.30} \\
\hline $\begin{array}{l}\text { High school or } \\
\text { equivalent }\end{array}$ & $189(36)$ & $31(28)$ & \\
\hline $\begin{array}{l}\text { Some college/ } \\
\text { Associate's degree }\end{array}$ & $106(21)$ & $25(25)$ & \\
\hline $\begin{array}{l}\text { College/advanced } \\
\text { degree }\end{array}$ & $69(24)$ & $30(35)$ & \\
\hline \multicolumn{4}{|l|}{ Income } \\
\hline$<\$ 20000$ & $336(48)$ & $74(54)$ & \multirow[t]{3}{*}{0.36} \\
\hline$\$ 20000-\$ 49999$ & $149(27)$ & $28(17)$ & \\
\hline$\$ 50000+$ & $72(25)$ & $23(29)$ & \\
\hline \multicolumn{4}{|c|}{ Private health insurance } \\
\hline Yes & 169 (40.2) & $46(40)$ & \multirow[t]{2}{*}{0.99} \\
\hline No & $388(59.8)$ & $79(60)$ & \\
\hline \multicolumn{4}{|c|}{ Adequate health literacy } \\
\hline Yes & $266(66)$ & $65(62)$ & \multirow[t]{2}{*}{0.58} \\
\hline No & $291(34)$ & $60(38)$ & \\
\hline \multicolumn{4}{|l|}{ Physical activity } \\
\hline Low & $322(53)$ & $63(52)$ & \multirow[t]{3}{*}{0.35} \\
\hline Medium & $204(40)$ & $48(32)$ & \\
\hline High & $31(7)$ & $14(15)$ & \\
\hline \multicolumn{4}{|l|}{ Healthy Eating Score§ } \\
\hline Low & $266(75)$ & $65(81)$ & \multirow[t]{2}{*}{0.46} \\
\hline High & $67(25)$ & $10(19)$ & \\
\hline \multicolumn{4}{|l|}{ Glycaemic control } \\
\hline Poor $(\mathrm{HbA} 1 \mathrm{c} \geq 7 \%)$ & $94(50)$ & $19(15)$ & \multirow[t]{2}{*}{0.0001} \\
\hline $\begin{array}{l}\text { Adequate } \\
(\mathrm{HbA} 1 \mathrm{c}<7 \%)\end{array}$ & $263(50)$ & $106(85)$ & \\
\hline \multicolumn{4}{|c|}{$\begin{array}{l}\text { *Not treated with prescription drugs but may be treated with diet } \\
\text { and exercise. } \\
\text { tWeighted column percentages are provided; percentages may } \\
\text { not add up to } 100 \% \text { due to rounding and total numbers may not } \\
\text { exactly add up as the average of } 15 \text { data sets are taken. } \\
\mp \chi^{2} \text { Test. } \\
\text { §Frequency missing }=274 \text {. } \\
\text { HbA1c, glycated haemoglobin. }\end{array}$} \\
\hline
\end{tabular}

untreated vs $50 \%$ for treated; $\left.\chi^{2} \mathrm{p}<0.001\right)$. We observed no overall associations between treatment status and income level, insurance status or level of health literacy.

Table 3 presents the use of hypoglycaemic medications among participants with physician-diagnosed type 2 diabetes in the overall BACH population and by race/ ethnicity. Five hundred and fifty-seven out of the 682 patients diagnosed with diabetes were on prescription regimens; approximately $20 \%$ of participants received no hypoglycaemic medications in the overall population and within racial/ethnic subgroups. The majority of participants on hypoglycaemic medications were prescribed biguanides $(65 \%)$, while $45 \%$ and $26 \%$ were prescribed insulin and sulfonylureas, respectively (alone or in combination). These proportions did not substantially differ across racial/ethnic subgroups ( $p$ values from $\chi^{2}$ tests: $0.22-1.00)$. While approximately $61 \%$ of the treated patients were prescribed only one class of hypoglycaemic medication, $32 \%$ were prescribed a combination of two, and $7 \%$ a combination of three or more. These values did not considerably differ by race/ethnicity ( $p$ values from $\chi^{2}$ tests: $\left.0.51-0.82\right)$. By treatment regimen, almost $80 \%$ of treated patients in total received biguanides only $(31 \%)$, insulin only (23\%), biguanides and insulin $(16 \%)$, or biguanides and sulfonylureas $(11 \%)$, and these regimens did not substantially vary across racial/ ethnic subgroups ( $p$ values from $\chi^{2}$ tests: $0.21-0.87$ ).

\section{Glycaemic control}

At the univariate level, African-American participants had the highest mean HbAlc levels (mean $\mathrm{HbAlc}=7.4 \%$; proportion $\geq 7 \%=49 \%$ ), while Hispanics had the highest proportion of uncontrolled diabetes (mean HbAlc $=7.2 \%$; proportion $\geq 7 \%=50 \%$ ). Non-Hispanic white participants were lowest on both these measures (mean $\mathrm{HbAlc}=6.9 \%$; proportion $\geq 7 \%=36 \%$ ). We observed the lowest mean HbAlc levels (6.4\%) among participants not receiving any hypoglycaemic medications (proportion with HbA1c $\geq 7=15 \%$ ). Among patients on medications, the best glycaemic control was among those treated with biguanides only (proportion with $\mathrm{HbAlc}<7 \%=70 \%$; mean HbAlc $=6.8 \%$ ), followed by patients treated with sulfonylureas only (proportion with $\mathrm{HbA1c}<7 \%=49 \%$; mean $\mathrm{HbAlc}=7.1 \%)$ and the worst among patients receiving a combination of biguanides, insulin and sulfonylureas ( proportion with $\mathrm{HbAlc}<7 \%=11 \%$; mean $\mathrm{HbAlc}=8.8 \%$ ). Participants prescribed insulin, either as a single drug or combined with other hypoglycaemic medications, had worse glycaemic control compared with individuals on other prescription regimens.

No associations between race/ethnicity and glycaemic control were observed in multivariable linear regression analyses overall (table 4). No associations between African-Americans and glycaemic levels were observed within most treatment regimens, and no associations between Hispanic-Americans and glycaemic levels were observed in any of the treatment regimens. However, African-Americans prescribed miscellaneous regimens had significantly elevated risk of poorer glycaemic control compared with non-Hispanic Caucasians. The results in table 4 are presented as a per cent difference. These results correspond to the following exponentiated regression coefficients $\left(\mathrm{e}^{\beta}\right)$, and 95\% CIs 1.06 (0.99 to 1.14 ) and 1.01 (0.90 to 1.13), respectively, for African- 
Table 3 Mutually exclusive antidiabetic treatment regimens among treated patients $(\mathrm{N}=557)$

\begin{tabular}{|c|c|c|c|c|c|}
\hline $\begin{array}{l}\text { Treatment } \\
\text { Number of medications }\end{array}$ & $\begin{array}{l}\text { Overall } \\
\mathrm{N}=682 \\
\mathrm{~N}(\%)^{\star}\end{array}$ & $\begin{array}{l}\text { Black } \\
N=254 \\
N(\%)^{*}\end{array}$ & $\begin{array}{l}\text { Hispanic } \\
\mathrm{N}=269 \\
\mathrm{~N}(\%)^{*}\end{array}$ & $\begin{array}{l}\text { White } \\
N=159 \\
N(\%)\end{array}$ & p Valuet \\
\hline 1 & $340(61)$ & $131(59)$ & $133(62)$ & $76(62)$ & 0.87 \\
\hline 2 & $176(32)$ & $63(36)$ & 77 (29) & $36(29)$ & 0.52 \\
\hline $3+$ & $41(7)$ & $10(5)$ & $18(9)$ & $13(8)$ & 0.51 \\
\hline Biguanides only & $174(31)$ & $63(30)$ & $69(33)$ & $42(30)$ & 0.86 \\
\hline Insulin only & $120(23)$ & $47(21)$ & $51(20)$ & $22(25)$ & 0.81 \\
\hline Insulin and biguanides only & 70 (16) & $23(14)$ & $34(16)$ & $13(17)$ & 0.87 \\
\hline Biguanides and sulfonylureas only & $70(11)$ & $25(12)$ & $27(9)$ & $18(11)$ & 0.69 \\
\hline Sulfonylureas only & $35(6)$ & $16(8)$ & $9(7)$ & $10(5)$ & 0.70 \\
\hline Insulin and sulfonylureas only & $11(3)$ & 7 (5) & $1(0)$ & $3(1)$ & 0.21 \\
\hline Biguanides, sulfonylureas and thiazolidinediones & $10(2)$ & $1(1)$ & $5(2)$ & $4(3)$ & 0.26 \\
\hline Biguanides, insulin and sulfonylureas & $15(2)$ & $4(2)$ & $6(3)$ & $5(2)$ & 0.82 \\
\hline Other regimens & $52(7)$ & $18(7)$ & $26(10)$ & $8(6)$ & 0.57 \\
\hline
\end{tabular}

*Weighted column percentages (may not add up to $100 \%$ due to rounding).

$+\chi^{2}$ Test.

Americans and Hispanic-Americans in the overall population; 1.03 (0.94 to 1.13 ) and 1.11 (0.97 to 1.26), respectively, among African-Americans and Hispanics treated with biguanides only; 1.04 (0.94 to 1.15$)$ and 1.08 (0.85 to 1.38), respectively, among AfricanAmericans and Hispanics treated with insulin only; 1.00 (0.96 to 1.16$)$ and 0.97 (0.84 to 1.13$)$, respectively, among African-Americans and Hispanics prescribed biguanides combined with either insulin or sulfonylureas; and 1.23 (1.07 to 1.43 ) and 1.11 (0.90 to 1.36), respectively, among African-Americans and Hispanics prescribed miscellaneous regimens.

Income status and having private insurance were not significantly associated with Hb1Ac levels in the analyses

Table 4 Associations between race/ethnicity and continuous $\mathrm{HbA1c}$ in the overall population and within individual drug regimens

\begin{tabular}{|c|c|c|c|}
\hline Treatment & $\begin{array}{l}\text { Model } 1^{*} \\
\text { Per cent difference }(95 \% \mathrm{Cl})\end{array}$ & $\begin{array}{l}\text { Model } 2 \dagger \\
\text { Per cent difference }(95 \% \mathrm{Cl})\end{array}$ & $\begin{array}{l}\text { Model } 3 \ddagger \\
\text { Per cent difference }(95 \% \mathrm{Cl})\end{array}$ \\
\hline \multicolumn{4}{|c|}{ Overall population $(\mathrm{n}=682)$} \\
\hline Black & $6.18(-1.00$ to 12.75$)$ & $5.13(-1.00$ to 11.63$)$ & $6.18(-1.00$ to 13.88$) \S$ \\
\hline Hispanic & $3.05(-3.92$ to 10.52$)$ & $3.05(-3.92$ to 9.42$)$ & $1.01(-9.52$ to 12.75$) \S$ \\
\hline White & Reference & Reference & Reference \\
\hline \multicolumn{4}{|c|}{ Biguanides only $(n=174)$} \\
\hline Black & 11.63 (1.01 to 22.14$)$ & 11.63 (1.01 to 24.61$)$ & $3.05(-5.82$ to 12.75$)$ \\
\hline Hispanic & $9.42(-1.00$ to 19.72$)$ & $9.42(0.00$ to 20.92$)$ & $10.51(-2.96$ to 25.86$)$ \\
\hline White & Reference & Reference & Reference \\
\hline \multicolumn{4}{|c|}{ Insulin only $(n=120)$} \\
\hline Black & $10.52(-5.82$ to 28.40$)$ & $6.18(-7.69$ to 23.37$)$ & $4.08(-5.82$ to 15.03$)$ \\
\hline Hispanic & $10.52(-5.82$ to 28.40$)$ & $0.00(-13.06$ to 15.03$)$ & $8.33(-14.79$ to 37.71$)$ \\
\hline White & Reference & Reference & Reference \\
\hline \multicolumn{4}{|c|}{ Biguanides combined with insulin or sulfonylureas $(n=140)$} \\
\hline Black & $-1.98(-14.79$ to 11.63$)$ & $5.13(-9.52$ to 11.63$)$ & $-0.09(-13.85$ to 15.86$)$ \\
\hline Hispanic & $-2.96(-14.79$ to 10.52$)$ & $5.13(-9.52$ to 11.63$)$ & $-2.96(-16.47$ to 12.75$)$ \\
\hline White & Reference & Reference & Reference \\
\hline \multicolumn{4}{|c|}{ Other miscellaneous drug regimens $(n=123)$} \\
\hline Black & $11.63(1.01$ to 23.37$)$ & $10.52(0.00$ to 20.92$)$ & 23.37 (7.25 to 43.33$)$ \\
\hline Hispanic & $2.02(-1.98$ to 16.18$)$ & $1.01(-11.31$ to 15.03$)$ & $10.52(-10.42$ to 36.34$)$ \\
\hline White & Reference & Reference & Reference \\
\hline \multicolumn{4}{|c|}{$\begin{array}{l}\text { `Estimates are adjusted for gender and age. } \\
\text { †Estimates are adjusted for gender, age and BMI. } \\
\text { †Estimates are adjusted for gender, age, BMI, education, adequate health literacy, private insurance, income, physical activity, diet, caloric } \\
\text { intake and DM duration. } \\
\text { §Additionally adjusted for treatment regimens: biguanides only, insulin only, biguanides combined with insulin or sulfonylureas, and other } \\
\text { regimens. } \\
\text { BMI, body mass index; DM, diabetes mellitus; HbA1c, glycated haemoglobin. }\end{array}$} \\
\hline
\end{tabular}


performed in the overall population (table 5). Younger patients and individuals with low levels of physical activity had elevated glycaemic levels compared with older patients and those who were more active, respectively (table 5). Results for the logistic regression analyses that evaluated associations between race/ethnicity and dichotomous HbA1c levels were mostly similar to the multivariable linear regression results, with no association between race/ethnicity and HbAlc levels in the overall population. However, we did not observe statistically significant increased risk of higher glycaemic levels among African-Americans within any of the treatment regimens (table 6). Our results for analyses performed in the overall population and within treatment strata remained essentially unchanged when the HbAlc threshold was increased to $\geq 8 \%$. However, we obtained wider CIs due to few participants in the HbAlc $\geq 8 \%$ category.

Additional information regarding the distribution of treatment regimens by disease duration and severity (see online supplementary table S1), and mean glycaemic levels in different treatment regimens (see online supplementary table S2), are provided in online supplementary tables.

\section{DISCUSSION}

In this study, we examined antidiabetic treatment regimens and glycaemic control by race/ethnicity among individuals with self-reported physician-diagnosed type 2 diabetes in the BACH cohort. We did not observe racial/ethnic differences in diabetes treatment patterns in this population. Furthermore, after multivariable adjustment, we did not observe racial/ethnic differences in glycaemic control overall, or within most treatment regimens. However, our findings suggested poorer glycaemic control among African-American patients prescribed miscellaneous regimens as compared with non-Hispanic Caucasians. Newer hypoglycaemic medications and combination regimens are often prescribed to patients resistant to first-line hypoglycaemic drugs such as metformin. Thus, these findings may indicate racial/ ethnic differences in glycaemic control among a subset of patients resistant to first-line hypoglycaemic medications. As data on racial/ethnic disparities in glycaemic control within diabetes treatment regimens are sparse in the literature, these results also call for further studies that examine such differences.

In contrast to our findings, studies conducted in other populations $^{3-10}$ have reported associations between race/ethnicity and glycaemic control. Some of these studies were conducted in populations that did not have universal healthcare coverage, ${ }^{36}$ which is a likely factor contributing to racial/ethnic disparities in diabetes treatment and management. However, certain studies conducted among insured participants ${ }^{7-10}$ have also found poorer glycaemic control among African-American patients with diabetes as compared with non-Hispanic
Table 5 Multivariable linear regression analyses results for percentage change in $\mathrm{HbA} 1 \mathrm{c}$ levels in the overall population* $(\mathrm{N}=682)$

\begin{tabular}{|c|c|}
\hline Variable & $\begin{array}{l}\text { Percentage change in } \\
\text { HbA1c levels ( } 95 \% \mathrm{Cls})\end{array}$ \\
\hline \multicolumn{2}{|l|}{ Race/ethnicity } \\
\hline Black & $6.18(-1.00$ to 13.88$)$ \\
\hline Hispanic & $1.01(-10.42$ to 12.75$)$ \\
\hline White & Reference \\
\hline \multicolumn{2}{|l|}{ Income } \\
\hline$<\$ 20000$ & 2.02 (-8.61to 13.88$)$ \\
\hline$\$ 20000-\$ 49999$ & 1.01 (-7.69to 9.42) \\
\hline$\$ 50000+$ & Reference \\
\hline \multicolumn{2}{|l|}{ Gender } \\
\hline Male & -1.98 (-6.76to 4.08) \\
\hline Female & Reference \\
\hline \multicolumn{2}{|l|}{ Private insurance $\dagger$} \\
\hline Yes & 2.02 (-6.76to 11.63) \\
\hline No & Reference \\
\hline \multicolumn{2}{|l|}{ Age } \\
\hline$\geq 65$ & $-14.79(-22.12$ to -7.69$)$ \\
\hline $55-64$ & $-14.79(-21.34$ to -6.76$)$ \\
\hline $34-54$ & Reference \\
\hline \multicolumn{2}{|l|}{ BMI category } \\
\hline Overweight $(25 \geq \mathrm{BMI}<30)$ & -3.92 (-15.63to 8.33) \\
\hline Obese $(\mathrm{BMI} \geq 30)$ & $-8.61(-18.13$ to 2.02$)$ \\
\hline Normal (BMI<25) & Reference \\
\hline \multicolumn{2}{|l|}{ Adequate health literacy } \\
\hline Yes & $-5.82(-12.19$ to 2.02$)$ \\
\hline No & Reference \\
\hline \multicolumn{2}{|l|}{ Education } \\
\hline Less than high school & $-5.82(-13.06$ to 3.05$)$ \\
\hline High school or equivalent & $-3.92(-10.42$ to 2.02$)$ \\
\hline $\begin{array}{l}\text { Some college/Associate's } \\
\text { degree }\end{array}$ & $-1.98(-9.52$ to 7.25$)$ \\
\hline College/advanced degree & Reference \\
\hline \multicolumn{2}{|l|}{ Physical activity } \\
\hline Low & 13.88 (4.08 to 23.37 ) \\
\hline Moderate & 12.75 (4.08 to 22.14$)$ \\
\hline High & Reference \\
\hline \multicolumn{2}{|l|}{ Healthy Eating Score } \\
\hline Low & $-1.00(-7.69$ to 7.25$)$ \\
\hline High & Reference \\
\hline \multicolumn{2}{|l|}{ Drug regimen } \\
\hline Biguanides only & $8.33(0.00$ to 16.18$)$ \\
\hline \multirow[t]{2}{*}{ Insulin only } & $19.72(6.18$ to 34.99$)$ \\
\hline & 20.92 (9.42 to 33.64$)$ \\
\hline Biguanides combined with & $17.35(10.52$ to 25.86$)$ \\
\hline insulin or sulfonylureas & $19.72(11.63$ to 28.40$)$ \\
\hline Other combinations & $8.33(0.00$ to 18.53$)$ \\
\hline No treatment & Reference \\
\hline
\end{tabular}

*Model adjusted for race/ethnicity, age, gender, income, education, diabetes duration (quadratic function), BMI, health insurance, adequate health literacy, diet, caloric intake and physical activity.

†Private and public insurance categories are not mutually exclusive.

$\mathrm{BMI}$, body mass index; HbA1c, glycated haemoglobin.

Caucasians. These findings may be due to reasons such as non-adherence, ${ }^{8-11}$ lack of self-monitoring ${ }^{4}$ or treatment differences that may exist within insured groups. Of note, many studies have found higher levels of non- 
Table 6 Associations between race/ethnicity and dichotomous $\mathrm{HbA1c}(\geq 7 \%$ vs $<7 \%)$ in the overall population and within individual treatment regimens

\begin{tabular}{|c|c|c|c|}
\hline & $\begin{array}{l}\text { Model } 1^{*} \\
\text { OR }(95 \% \mathrm{Cl})\end{array}$ & $\begin{array}{l}\text { Model 2† } \\
\text { OR }(95 \% \mathrm{Cl})\end{array}$ & $\begin{array}{l}\text { Model 3‡ } \\
\text { OR (95\% CI) }\end{array}$ \\
\hline \multicolumn{4}{|c|}{ Overall population $(n=682)$} \\
\hline Black & 1.71 (0.90 to 3.23$)$ & 1.65 (0.86 to 3.14$)$ & $1.28(0.45$ to 3.65$) \S$ \\
\hline Hispanic & $1.78(0.90$ to 3.55$)$ & 1.77 (0.89 to 3.49$)$ & 1.07 (0.24 to 4.77$) \S$ \\
\hline White & Reference & Reference & Reference \\
\hline \multicolumn{4}{|c|}{ Biguanides only $(n=174)$} \\
\hline Black & $3.50(0.89$ to 13.74$)$ & 3.51 (0.90 to 13.73$)$ & 0.81 (0.08 to 7.94$)$ \\
\hline Hispanic & $2.70(0.63$ to 11.47$)$ & $2.73(0.66$ to 11.24$)$ & $1.90(0.19$ to 18.87$)$ \\
\hline White & Reference & Reference & Reference \\
\hline \multicolumn{4}{|c|}{ Insulin only $(n=120)$} \\
\hline Black & $3.56(0.84$ to 15.15$)$ & $2.86(0.62$ to 13.21$)$ & $1.39(0.10$ to 20.16$)$ ๆ \\
\hline Hispanic & $4.24(0.73$ to 24.79$)$ & 3.24 (0.47 to 22.35$)$ & $0.65(0.07$ to 5.82$)$ ר \\
\hline White & Reference & Reference & Reference \\
\hline \multicolumn{4}{|c|}{ Biguanides combined with insulins or sulfonylureas $(n=140)$} \\
\hline Black & $0.78(0.19$ to 3.09$)$ & $0.73(0.14$ to 3.77$)$ & $0.08(0.00$ to 4.98$)$ \\
\hline Hispanic & $0.97(0.17$ to 5.35$)$ & $0.87(0.15$ to 5.07$)$ & 0.04 (0.00 to 4.49$)$ \\
\hline White & Reference & Reference & Reference \\
\hline \multicolumn{4}{|c|}{ Other miscellaneous drug regimens $(n=123)$} \\
\hline Black & $3.31(0.72$ to 15.18$)$ & $2.68(0.57$ to 12.56$)$ & $9.71(0.79$ to 119.26$)$ q \\
\hline Hispanic & $3.15(0.52$ to 19.13$)$ & 2.54 (0.38 to 16.79$)$ & 2.97 (0.09 to 95.17$)$ ๆ \\
\hline White & Reference & Reference & Reference \\
\hline \multicolumn{4}{|c|}{$\begin{array}{l}\text { *Adjusted for gender and age. } \\
\text { †Adjusted for gender, age and BMI. } \\
\text { †Adjusted for gender, age, BMI, insurance status, adequate health literacy, educational level, diet, caloric intake, physical activity and DM } \\
\text { duration. } \\
\text { §Additionally adjusted for treatment regimens (biguanides only, insulin only, biguanides combined with insulin or sulfonylureas, and other } \\
\text { regimens). } \\
\text { INot adjusted for Healthy Eating Score to preserve model stability. } \\
\text { BMI, body mass index; DM, diabetes mellitus; HbA1c, glycated haemoglobin. }\end{array}$} \\
\hline
\end{tabular}

adherence among African-American patients with diabetes as compared with non-Hispanic Caucasians. ${ }^{9-11}$ We are unable to assess the extent to which these factors impacted our findings, with the exception of diabetes treatment, which did not vary by race/ethnicity. However, had such differences existed, they are unlikely to have strongly impacted our study findings, given our null results.

We observed the lowest HbAlc levels among participants not on any hypoglycaemic medications followed by those taking biguanides, and the highest among participants prescribed insulin regimens. These findings agree with current prescription patterns of hypoglycaemic medications, as patients with less severe disease are often encouraged to engage in lifestyle changes and/or are prescribed metformin, a biguanide, as a firstline antidiabetic drug. ${ }^{32}$ Insulin, on the other hand, is generally prescribed to patients with more severe disease. $^{32}$ Compared with the utilisation of hypoglycaemic drugs among treated patients with diabetes in the 2007 Medical Expenditure Panel Survey (MEPS), ${ }^{33}$ thiazolidinedione and sulfonylurea use was lower in the BACH cohort (thiazolidinediones: $6 \%$ for any regimen in BACH vs 25\% in MEPS for 2007; sulfonylureas: $26 \%$ in BACH for any regimen vs $40 \%$ in MEPS for 2007), while biguanide use was higher $(65 \%$ for any regimen in
BACH vs 55\% in MEPS for 2007) as was insulin (45\% in any regimen in BACH vs $24 \%$ for MEPS in 2007). The latter may represent a switch back from thiazolidinediones to older drugs following safety concerns. ${ }^{14} 34$

The overall percentage of participants with $\mathrm{HbAlc}$ levels $\geq 7 \%$ in our study $(43 \%)$ was lower than that reported in National Health and Nutrition Examination Survey (NHANES) 2007-2010 for adults with diagnosed diabetes $(48 \%) .^{2}$ The observed mean differences in HbAlc levels between African-American and white participants, and Hispanic-American and white participants, in our study, were $0.5 \%$ and $0.3 \%$, respectively. These values were lower than the mean differences reported between African-Americans and Caucasians, and Hispanic-Americans and Caucasians, in a meta-analysis of 11 studies $\left(0.65 \%\right.$ and $0.50 \%$, respectively). ${ }^{5}$

Our study is not without limitations. First, the small number of study participants within some treatment regimens may have reduced our power to detect significant associations. As our analyses performed within treatment strata had sufficient power to detect only strong associations, lack of statistical power should be considered one plausible alternative in light of our negative findings. Second, we had no Asians or Native-Americans who may be at increased risk for diabetes compared with non-Hispanic Caucasians in our study population. ${ }^{1}$ 
We excluded Asians from the study population due to their relatively smaller numbers in Boston and the complexities of recruiting sufficient representation from Asian population subgroups. Third, as our study population consisted of only a few participants who were uninsured $(\mathrm{n}=11),{ }^{35}$ we were unable to assess the influence of being uninsured on diabetes treatment and glycaemic control. Thus, our results may not be generalisable to other areas of the USA with greater proportions of uninsured participants. Finally, as we assessed HbAlc levels at a single point in time, we were unable to evaluate longitudinal changes in glycaemic levels across racial/ethnic subgroups.

Our study had countervailing strengths: First, BACH is a community-based racially/ethnically diverse sample suited to evaluate racial/ethnic disparities in medication utilisation. Second, we obtained detailed information on hypoglycaemic medication use in our study population that was directly assessed by interviewers. Third, we were able to accurately assess actual utilisation of these medications rather than mere prescription events by directly questioning participants and by examining medication containers.

\section{CONCLUSION}

In a highly insured (>99\%) population, HbA1c levels were similar across race/ethnicity in the overall population and within most treatment regimens. These results may in part be explained by the lack of racial/ethnic differences in diabetes treatment regimens in this population. To the best of our knowledge, this is among the first population-based studies to examine racial/ethnic disparities in diabetes treatment after implementation of the MA Healthcare Reform Act in 2006. As more Americans are being insured under the Affordable Care Act, studies are needed to track changes in treatment patterns over time by race/ethnicity to understand the impact of insurance coverage on treatment and racial/ ethnic disparities in diabetes outcomes. ${ }^{35}$

Contributors JBM conceived the study questions. SDG and SAH developed the study design and analysis plan with input from SCF, RSP and JBM. SDG and MHY analysed the data. SDG drafted the manuscript. All authors reviewed and provided input to the article, contributed to interpretation of the findings and approved the version submitted for publication.

Funding This project was supported by awards DK056842 and DK080786 from the National Institute of Diabetes and Digestive and Kidney Diseases.

Competing interests SAH is now an employee of and has equity interest in Biogen Idec.

Patient consent Obtained.

Ethics approval New England Research Institutes' Institutional Review Board.

Provenance and peer review Not commissioned; externally peer reviewed.

Data sharing statement No additional data are available.

Open Access This is an Open Access article distributed in accordance with the Creative Commons Attribution Non Commercial (CC BY-NC 4.0) license, which permits others to distribute, remix, adapt, build upon this work noncommercially, and license their derivative works on different terms, provided the original work is properly cited and the use is non-commercial. See: http:// creativecommons.org/licenses/by-nc/4.0/

\section{REFERENCES}

1. Centers for Disease Control and Prevention. National Diabetes Statistics Report: estimates of diabetes and its burden in the United State. Atlanta, GA: US Department of Health and Human Services, 2014. http://www.cdc.gov/diabetes/pubs/statsreport14/ national-diabetes-report-web.pdf (accessed 15 Aug 2014).

2. Stark Casagrande S, Fradkin JE, Saydah SH, et al. The prevalence of meeting A1C, blood pressure, and LDL goals among people with diabetes, 1988-2010. Diabetes Care 2013;36:2271-9.

3. Heisler M, Faul M, Hayward RA, et al. Mechanisms for racial and ethnic disparities in glycemic control in middle-aged and older Americans in the health and retirement study. Arch Intern Med 2007;167:1853-60.

4. Campbell JA, Walker RJ, Smalls BL, et al. Glucose control in diabetes: the impact of racial differences on monitoring and outcomes. Endocrine 2012;42:472-82.

5. Kirk JK, Passmore LV, Bell RA, et al. Disparities in HbA1c levels between African-American and non-Hispanic white adults with diabetes: a meta-analysis. Diabetes Care 2006;29:2130-6.

6. Saydah S, Cowie C, Eberhardt MS, et al. Race and ethnic differences in glycemic control among adults with diagnosed diabetes in the United States. Ethn Dis 2007;17:529-35.

7. Egede LE, Gebregziabher M, Hunt KJ, et al. Regional, geographic, and racial/ethnic variation in glycemic control in a national sample of veterans with diabetes. Diabetes Care 2011;34:938-43.

8. Adames AS, Zhang F, Mah C, et al. Race differences in long-term diabetes management in an HMO. Diabetes Care 2005;28:2844-9.

9. Adams AS, Trinacty CM, Zhang F, et al. Medication adherence and racial differences in HbA1c control. Diabetes Care 2008;31:916-21.

10. Egede LE, Gebregziabher M, Echols C, et al. Longitudinal effects of medication nonadherence on glycemic control. Ann Pharmacother 2014;48:562-70.

11. Egede LE, Lynch CP, Gebregziabher M, et al. Differential impact of longitudinal medication non-adherence on mortality by race/ethnicity among veterans with diabetes. J Gen Intern Med 2013;28:208-15.

12. Sarpong EM, Bernard DM, Miller GE. Changes in pharmaceutical treatment of diabetes and family financial burdens. Med Care Res Rev 2012;69:474-91.

13. Alexander GC, Gallagher SA, Mascola A, et al. National trends in treatment of type 2 diabetes mellitus, 1994-2007. Arch Intern Med 2008;168:2088-94.

14. Agency for Healthcare Research and Quality. Effective Health Care Program. Comparing medications for adults with type 2 diabetes. http://www.effectivehealthcare.ahrq.gov/ehc/products/155/720/ ECBCM_Oral\%20Meds\%20T2\%20Diab_Clinician06282011.pdf (accessed 7 Oct 2014).

15. Pawlyk AC, Giacomini KM, McKeon C, et al. Metformin pharmacogemomics: current status and future directions. Diabetes 2014;63:2590-9.

16. Esposito K, Chiodini P, Bellastella G, et al. Proportion of patients at $\mathrm{HbA1c}$ target \&lt; $7 \%$ with eight classes of antidiabetic drugs in type 2 diabetes: systematic review of 218 randomized controlled trials with 78945 patients. Diabetes Obes Metab 2012;14:228-33.

17. Williams-Herman D, Johnson J, Teng R, et al. Efficacy and safety of sitagliptin and metformin as initial combination therapy and as monotherapy over 2 years in patients with type 2 diabetes. Diabetes Obes Metab 2010;12:2590-9.

18. Deeks ED, Scott LJ. Pioglitazone/metformin. Drugs 2006;66: 1863-77; Discussion: 1878-80.

19. Tosi F, Muggeo M, Brun E, et al. Combination treatment with metformin and glibenclamide versus single-drug therapies in type 2 diabetes mellitus: a randomized, double-blind, comparative study. Metabolism 2003;52:862-7.

20. Heisler M, Smith DM, Hayward RA, et al. Racial disparities in diabetes care processes, outcomes, and treatment intensity. Med Care 2003;41:1221-32.

21. Piccolo RS, Araujo AB, Pearce N, et al. Cohort profile: the Boston Area Community Health $(\mathrm{BACH})$ survey. Int $J$ Epidemiol 2014;43:42-51.

22. McKinlay JB, Link CL. Measuring the urologic iceberg: design and implementation of the Boston Area Community Health $(\mathrm{BACH})$ Survey. Eur Urol 2007;52:389-96.

23. West SL, Strom BL, Poole C. Validity of Pharmacoepidemiologic Drug and Diagnosis Data. In: Strom BL, ed. Pharmacoepidemiology. 4th edn. John Wiley \& Sons, 2005:709-65.

24. National Institute of Diabetes and Kidney Diseases. Harmonizing hemoglobin A1c testing. http://www.ngsp.org/ADA.asp (accessed 10 Oct 2014).

25. American Diabetes Association. Diabetes Care. Standards of Medical Care in Diabetes_2014. http://care.diabetesjournals.org/ content/37/Supplement_1/S14.full (accessed 17 Sep 2014). 
26. Centers for Disease Control and Prevention. Healthy weight-it is not a diet, it is a lifestyle. http://www.cdc.gov/healthyweight/ assessing/bmi/adult_bmi/index.html\#Interpreted (accessed 29 Oct 2014).

27. Baker DW, Williams MV, Parker RM, et al. Development of a brief test to measure functional health literacy. Patient Educ Couns 1999;38:33-42.

28. Physical Activity Scale for the Elderly (PHASE). http://www. framinghamheartstudy.org/share/protocols/bmd1_7s_protocol.pdf (accessed 6 Aug 2014).

29. Block G, Hartman AM, Dresser CM, et al. A data-based approach to diet questionnaire design and testing. Am J Epidemiol 1986;124:453-69.

30. van Buuren S, Groothuis-Oudshoorn K. MICE: Multivariate Imputation by Chained Equations in R. J Stat Software 2011;45:1-67.
31. Heeringa S, West BT, Berglund PA. Applied survey data analysis. Boca Raton, FL: CRC Press, 2010.

32. Redmon B, Caccamo D, Flavin P, et al. Institute for Clinical Systems Improvement. Diagnosis and management of type 2 diabetes mellitus in adults. Updated July 2014. https://www.icsi.org/_asset/ 3rrm36/diabetes-interactive0412.pdf (accessed 2 Oct 2014).

33. Agency for Healthcare Research and Quality. U.S. Department of Health and Human Services. Trends in pharmaceutical treatment of diabetes, 1997-2007. The Medical Expenditure Panel Survey (MEPS). http://meps.ahrq.gov/mepsweb/data_files/publications/rf30/ rf30.pdf (accessed 14 Aug 2014).

34. Kung H, Henry RR. Thiazolidinedione safety. Expert Opin Drug Saf 2012;11:565-79.

35. Tinsley LJ, Hall SA, McKinlay JB. Has Massachusetts health care reform worked for the working poor? Results from an analysis of opportunity. Ann Epidemiol 2014;213:312-18. 